\title{
Humanitarian aid workers' knowledge of minority cultures in Iraqi Kurdistan
}

Kyle A. Msalli(i)

\begin{abstract}
The Yezidi population in northern Iraq has faced genocide by the Islamic State of Iraq and al-Sham (ISIS), have been driven from their homes, and forced to take refugee anywhere that is deemed safe. The current study focused on the humanitarian organizations that provided aid to this population to understand if humanitarian aid workers had appropriate knowledge of the Yezidi culture. Questionnaires were completed by 37 local aid workers. Findings suggested that the aid workers did not have a sufficient understanding of the Yezidi culture due to the lack of cultural awareness training given by humanitarian organizations.
\end{abstract}

Keywords: Displacement, Minority cultures, Cultural awareness, Aid workers, Cultural relevancy

\section{Introduction}

The humanitarian crisis in the Middle East increased dramatically with the Islamic State of Iraq and al-Sham (ISIS) in 2014. During this time, around 1 million individuals were forced to flee their homes because of ISIS. Although a large influx began in 2014, mass displacement has been a recurring theme in the Middle East for a couple of decades (Mowafi 2011). This has forced many different populations from their homes which leads them to find refuge wherever they are able usually among urban areas with no way of supporting themselves (Sa'Da and Serafini 2013). In one case, ISIS surrounded and conducted mass killings and kidnappings of Yezidis around Sinjar. Today, there are roughly 400,000 Yezidi internally displaced persons (IDPs) in the Dohuk region of Iraq with the majority of these individuals living outside of IDP camps. Many of these individuals come in contact with some sort of humanitarian organization, and the individuals residing in the camps are often in contact with these organizations daily.

\section{Yezidis: a brief introduction}

Although they are thought of as ethnically Kurdish, many Yezidis identify as a distinct ethnicity with the United Nations also recognizing the Yezidis as a distinct ethnic group (Levinson 1998; UNHCR 2007). The definition of ethnicity is a much-debated topic in the

Correspondence: kyle.msall@gmail.com

American University of Kuwait, P.O. Box 3323, 13034 Safat, Kuwait academic and legal fields with the United Nations (1998) recommending that each country should apply the definition of ethnicity and criteria of ethnic characteristics that are determined by the groups that it aims to identify, in this case, the Yezidis. Yezidis have religious views, cultural norms, and values different from the vast majority of the refugees housed in Iraqi Kurdistan, making them unique within the IDP population in Iraqi Kurdistan (Maisel 2013).

According to Dalyan and Dogan (2013), while there is no consensus among researchers and historians as to the ethnicity of Yezidis, most academic studies tend to accept that the Yezidi people are Near Eastern in terms of ethnicity. The Yezidis have been living in the mountains of northwestern Iraq for centuries, but their population has been on a steady decline since the Saddam Hussein era of Iraq (Açikyildiz 2014). Throughout the region, they are often referred to as devil worshipers due to their archangel having a close resemblance to the same angel in Islam (and other religions such as Christianity) that refused to kneel before Adam, which Muslims perceive as being associated with Satan. Iraqi Yezidis live in northern Iraq where their holy city, Lalish, is located northeast of Mosul in northern Iraq. Although some of their customs are similar to other religions (i.e., not eating pork), they have unique customs as well. Some of these customs are, for example, that they believe they are descended only from Adam and not from Eve and they do not accept any converts to their religion (Açikyildiz 2014). 
Yezidism as a distinct religion is debated among academics and researchers because it has been orally transmitted from generation to generation until the early twentieth century when the two holy books were published: Yezidi Black Book and Book of Revelation (Guest 1993). The Yezidi religious beliefs and customs also vary from region to region and are based on oral tradition, which makes understanding Yezidism difficult for outsiders (Spät 2008). The belief system of Yezidism contains similar aspects of several religions including Christianity, Islam, and Zoroastrianism. However, the distinctiveness of Yezidi religion is based on the worship of the Peacock Angel or Taus Melek, which is the leader of the seven angels the Yezidi God sent down to Earth to protect it (Açikyildiz 2014). This has been prominent in the persecution of the Yezidis who are perceived as devil worshippers (Açikyildiz 2014; Spät 2008).

Yezidism is known to be a secretive religion in which outsiders are usually only provided with superficial information about the religion and kept from its inner workings (Nicolaus 2011). This secrecy is also claimed in the Yezidi holy books which Guest (1993) explored. Although it is generally accepted by academics that these books were forgeries because they were written by non-Yezidis, they do, however, contain many aspects of the Yezidi religion and culture throughout the texts. Such secretiveness among the Yezidis about their religion serves an accommodative function of ascertaining a common language between Yezidi people who would otherwise perhaps be enemies by declaring their own religion above and more absolute over others, which could be similar to other religions in the region that deem their beliefs as the correct religion (Nicolaus 2011).

Yezidism has several important religious practices, rituals, and observations that Yezidis follow, with the most important being the rite of the haircut, baptism, circumcision, brother or sister of the hereafter, the wedding, and funeral (Açikyildiz 2014). There are several other aspects of Yezidism that are similar to other religions, such as praying multiple times a day in the direction of the sun, the pilgrimage that all Yezidis are required to make to Lalish if they are able, and periods of fasting (which both Christianity and Islam also have). Also, some taboos and practices in Yezidism are similar to those found in the Zoroastrian religion, including cleanliness, worshiping the sun, prohibition of marriage outside their religion, and eating unclean foods (similar to the Yezidi explanation of not eating certain vegetables) (Açikyildiz 2014; Guest 1993).

The lifestyle of the Yezidi population varies across regions with some populations still living the nomadic lifestyle and others, mostly the younger generation, attempting to assimilate into the Kurdish population (Rydgren and Sofi 2011). The nomadic lifestyle of some
Yezidis seems to begin with their religious belief that contact with others makes one less of a Yezidi. However, the invasion of ISIS across northern Iraq has led to an influx of Yezidi IDPs into Kurdistan, which has thus uprooted the Yezidi way of life and forced a sudden change among the entire population in Iraq. With many populations around the region believing that Yezidism is a religion of devil worship, Yezidis have been discriminated against throughout the history, and most recently, ISIS declared genocide against them.

\section{The Yezidi minority population and NGOs}

Because the Yezidi population is a minority population in Iraq and much different culturally and religiously than the other populations found within Iraq, the challenges they face are not only due to the genocide from ISIS but also dealing with displacement amidst a culture that is different from their own. Although most humanitarian organizations are well-intentioned, the fact that their programs may not be culturally relevant and the aid workers may not be culturally aware of the minority populations may lead to more harm than good. This is a concern not just with the Yezidi population in Iraq but for all minority populations who are displaced. Although there are several international guidelines that provide humanitarian organizations with the basic steps to develop cultural relevancy within their organization, the general suggestion is to have local aid workers involved in the organizations' programs who speak the local language (CHS 2014).

There are several major efforts to establish these guidelines and standards for these organizations working with refugees and IDPs including the Sphere Project, the Core Humanitarian Standard (CHS), the Inter-Agency Standing Committee (IASC), and the Humanitarian Accountability Project (HAP). The goal of these different projects and guidelines is to ensure the accountability of humanitarian agencies toward their constituents, donors, and affected populations; improve the quality of humanitarian aid and organizations; and provide guidelines for specific aid needed such as the Guidelines of Mental Health and Psychosocial Support in Emergency Settings by the IASC (CHS 2014; IASC 2007; HAP 2010; Sphere Project, 2016).

For instance, when discussing about internationalizing Western practices, Dominelli (2014) suggested that the people who demonstrated that they needed or wanted help in disaster areas were more inclined to want and prefer programs that were focused on their culture and locality as well as culturally relevant forms of the programs offered. The specifics on how to adopt a program and implement local culture within a program or service are not rigid and really depend on the culture that organization is working with. However, Facchini (2013) 
reported that these cultural awareness programs with humanitarian aid organization are essential because the target population's culture takes into account the health care system, which includes not only primary and mental health care providers but also recipients and, more importantly, the culture's perception of health, illness, and wellness along with traditional medicine. Further, it was found that assessments of pre-deployment trainings pertaining to cultural awareness among the personnel greatly improved in addition to increasing capacity building, aid, and training of indigenous personnel (Facchini 2013). This offered solid points that cultural awareness training among humanitarian aid and capacity-building personnel was a success and increased their ability to do their job. Facchini (2013) posited that "to health care personnel intervening in a host nation, diagnosing and treating the illness should be just as important as reintegrating the individual into his or her culture (p. 539)."

Although these guidelines and projects are there for humanitarian organizations to develop a better service to the target population, it seems that many humanitarian organizations do not strive to follow these suggestions. This was found among the Yezidi population in Iraq in a recent study which interviewed Yezidi displaced persons. The findings suggested that the Yezidi population in Iraq lacked the services that other ethnicities were receiving, and the services that were received were viewed as poor quality (Msall 2016). The Yezidi participants related this lack of services and poor quality with the reason that their population was being discriminated against by the local majority population and the local governmental and nongovernmental organizations. This is an example of how non-culturally relevant humanitarian organizations may do more harm than good in certain situations.

Previous studies have suggested that displaced minority populations have a higher risk of developing traumatic psychological responses and facing discrimination from the local host population (Betancourt et al. 2009). Minority displaced groups in similar situations as the Yezidis have been forced to deal with these issues in locations such as Bosnia, Croatia, and Israel (Daoud et al. 2012; Koska 2008; Roumani 2003). In addition to discrimination and traumatic psychological issues, minority displaced populations are at a higher risk of minority rights abuses (Choi and Piazza 2014; Reuter 2012). Although the guidelines mentioned above seek to prevent such instances from happening, the reality is that most organizations tend to not be aware of the potential harm that could result from not having non-culturally relevant programs for their target population.

However, designing a culturally relevant program with the Yezidi population could be a challenge for the organizations because of the lack of research that has been done on the population. Bender et al. (2014) suggested that in order to develop and design a program that is culturally relevant to a certain population, the organization or individual must be culturally sensitive and take into account the ethnic and cultural characteristics including values, religious beliefs, behaviors, family and social framework, and literacy and education levels of the population. The most important and relevant one for the Yezidi IDPs seems to be the aspect of religious beliefs since the Yezidi culture is so intertwined with their religious views, as discussed in the previous sections.

Furthermore, to understand how to provide services that are culturally relevant to a given population, the leaders and organizations working there must research and recognize how the specific culture conceptualizes and works through mental health issues that arise due to trauma (Copping et al. 2010). There have been several isolated studies recently in different parts of the world that have studied the indigenous culture of the NGO's target population and then have implemented those findings into the NGO's programs (Bender et al. 2014; Betancourt and Williams 2008; Sonderegger et al. 2011). These studies primarily focused on researching the cultural differences, hiring local staff, and using the local language within the NGO programs. However, as Abramowitz (2010) suggested, humanitarian systems are not necessarily locally relevant with simply embedding local languages and employing local staff but require a foundation in field research of that target population to not only address the language barrier but also to address the meaning barrier for the NGOs and health providers. The current study addressed the issue of local staff and local language in NGOs and suggests that these are not the basis for the cultural understanding of the Yezidi minority population.

\section{Method}

To better understand the knowledge of Yezidi cultural aspects among humanitarian aid workers, 37 quantitative questionnaires were completed by local humanitarian aid workers from five organizations within Iraqi Kurdistan. The main goal of the study was to understand if the humanitarian organizations provided cultural awareness training to the aid workers and if Yezidi cultural aspects were implemented into the programs. Both international and local nongovernmental humanitarian organizations were represented in the sample with all humanitarian aid workers being local residents.

\section{Setting}

The location for the data collection was in northeastern Iraq or Iraqi Kurdistan. The data collection took place in 
mid-June 2015 which was almost a year after ISIS initially carried out its operation in Iraq. The overall interactions with the participants took place during daylight hours in such environmental conditions as high heat levels (over $100{ }^{\circ} \mathrm{F}$ ), often a dusty atmosphere, and undeveloped roads. For the data collection, three different IDP camps were visited along with two nongovernmental organizations (NGOs) outside of the camps. Questionnaires were conducted in the camp headquarters or at the NGO headquarters outside the camps where the humanitarian aid workers were invited to participate.

\section{Sample}

The quantitative study sample consisted of 37 humanitarian aid workers in Iraqi Kurdistan. The participants were grouped by the ethnicity into either Yezidi $(n=5)$ or non-Yezidi $(n=32)$. The organizations consisted of two different types of NGOs: local $(n=3)$ and international $(n=2)$.

As the participants who were Yezidi scored nearly $100 \%$ on the questionnaire, they were removed from some tests and used as a control group between the non-Yezidis. The non-Yezidi group also had differences, such as participants who had experience working with Yezidis $(n=11)$ and participants who had no experience working with Yezidis $(n=21)$.

\section{Instruments}

The questionnaire used was developed by the research and based on prior research and evidence-based guidelines and standards for humanitarian organizations. These included the Inter-Agency Standing Committee Guidelines on Mental Health and Psychosocial Support in Emergency Settings (IASC 2007) and the Core Humanitarian Standard. One strength of using questionnaires for this study was to be able to obtain as many participants as possible in the allotted time. Questionnaires are only as strong as the questions asked which is why this particular questionnaire was based on already proven guidelines as mentioned above. However, a limitation of questionnaires in general is the lack of specific details. In this case, the questionnaire cannot fully capture the reason for the lack of knowledge about the Yezidi culture or particular cultural differences between the Yezidis and the participants. A qualitative approach would need to be conducted as a future study to obtain these details.

\section{Results}

\section{Comparative analysis of the knowledge of the Yezidi culture}

Initially, the quantitative data were examined to check the assumptions for the analysis of variance (ANOVA) and for the multivariate analysis of variance (MANOVA) $I$ tests that were planned to identify the between- and within-group differences. However, the data did not meet the assumptions of homoscedasticity and normal distribution required for these tests due to the limited sample size. The homoscedasticity assumption was measured using Levene's test, which showed the significance of $p$ value thus demonstrating that the sample variances were unequal. Therefore, the second part of the data analysis strategy, the use of nonparametric tests equivalent to ANOVA and MANOVA that do not require meeting such assumptions, was executed.

The first research question for the quantitative study was "What types of humanitarian organizations provide cultural awareness training for aid workers focusing on the minority Yezidi culture?" It was predicted that international humanitarian organizations may provide basic cultural awareness training for aid workers but not concerning the minority Yezidi culture, as well as local NGO humanitarian programs although may have knowledge of Yezidi culture, do not implement cultural awareness training for the aid workers. The data collection and analysis partially supported the hypothesis of the first research question showing that neither international nor local humanitarian organizations provided cultural awareness training for aid workers concerning the minority Yezidi culture. As predicted, despite the lack of cultural awareness training, local aid workers did have some knowledge of Yezidi culture, which is analyzed below.

The second research question was "What types of humanitarian organizations provide culturally relevant humanitarian programs to the Yezidi IDPs?” It was expected that international humanitarian organizations do not provide culturally relevant humanitarian programs to the Yezidi IDPs, while local humanitarian NGOs may implement basic cultural aspects into their programs. Again, the data provided partial support of the hypothesis for this research question showing that international humanitarian organizations did not provide culturally relevant humanitarian programs to the Yezidi IDPs. This was true for local NGOs as well, although they were expected to implement basic cultural aspects into their programs, as recommended in IASC guidelines (IASC 2007), the results suggest that it was not apparent that the local organizations did so.

Based on the theoretical analysis of the reviewed humanitarian literature, four types of humanitarian organizations were identified and described. Any or all of the four types of organizations and programs were expected to emerge through the quantitative data analysis:

1. The model type (MT) of organizations that provide both cultural awareness training for their workers and culturally relevant programs for the Yezidi IDPs.

2. Cultural training (CT) but not program type of organizations that provide cultural awareness training to their 
workers, but do not implement culturally relevant programs for the Yezidi IDPs. It was predicted that this type may apply to international humanitarian organizations.

3. Culturally relevant programs (CRP) but no training type of organizations that do not provide cultural awareness training to their workers, but do implement culturally relevant programs for the Yezidi IDPs. It is expected that this type may apply to local governmental and nongovernmental organizations.

4. No cultural relevance (NCR) type of organizations that do not provide cultural awareness training to their workers and do not implement culturally relevant programs for the Yezidi IDPs. It was expected that most organizations would be included in this type.

The data analysis revealed that only NCR type of humanitarian organizations was presented on the ground in Iraqi Kurdistan, which did not provide cultural awareness training for their workers and did not implement culturally relevant programs for the Yezidi IDPs. However, aid workers had some knowledge of Yezidi culture, as was predicted.

To evaluate possible differences in the knowledge of Yezidi culture among aid workers based on their experience of working with Yezidi IDP population, three groups of aid workers were compared: non-Yezidi aid workers who had experience working with Yezidi IDPs, non-Yezidi aid workers who did not have experience working with Yezidi IDPs, and Yezidi aid workers. The total scores on the humanitarian questionnaire, which included 22 questions, were calculated for each participant.

First, Kruskal-Wallis test revealed that participants' knowledge of Yezidi culture based on their total scores on the humanitarian questionnaire differed significantly across the three groups of participants, $X^{2}(2, N=37)=13.62, p<.05$.

However, this included the Yezidi participants, which made the results skewed toward their knowledge in relation to non-Yezidi participants' knowledge. The Kruskal-Wallis test was conducted again by using only the two non-Yezidi groups to determine if there was a significant difference between them. The findings showed that there was no significant difference in the total scores on the humanitarian questionnaire between the two non-Yezidi groups of local participants in their knowledge of Yezidi culture, $X^{2}(1, N=32)=1.283, p=0.257$. This finding was further confirmed with a Mann-Whitney $U$ test also indicating that there was no significant difference between participants' knowledge of Yezidi culture with regard to their experience of working with Yezidi IDPs $(U=87, \mathrm{~N} 1=21, \mathrm{~N} 2=11, p=0.271$, two-tailed).

Next, the Kruskal-Wallis test was conducted to compare the scores on each of the 22 variables among the non-Yezidi participants who did or did not have experience working with Yezidi IDPs. Eight variables, as shown in Table 1, indicated significant differences between the two groups. The aid workers with experience of working with Yezidi IDPs reported having better knowledge of the foods restricted in Yezidi culture, Yezidi eating rituals, and fasting practices. The aid workers who did not have experience working with Yezidi IDPs reported having better knowledge of Yezidi perceptions and treatment of persons with physical disabilities, Yezidi conceptualizations of mental disorders and indigenous healing practices used to treat them, and Yezidi communication requirements such as proximity in nonverbal communication in addition to behaviors that are perceived most respectful and disrespectful in Yezidi culture.

A Kruskal-Wallis test was also conducted to understand if there was a significant difference in total scores of the humanitarian questionnaire between the two types of organizations that the participants were a part of, international NGOs and local NGOs. The test revealed that there was no significant difference in the total score of the humanitarian questionnaire between aid workers based on the type of organization.

These findings formed the answer to research question 1 and supported hypothesis 1 which suggested that no cultural awareness training was offered by the

Table 1 Comparison on the knowledge of Yezidi culture among aid workers in Iraqi Kurdistan

\begin{tabular}{|c|c|c|c|}
\hline \multirow[t]{2}{*}{ Question } & \multirow[t]{2}{*}{ Significance } & \multicolumn{2}{|l|}{ Mean rank } \\
\hline & & No Yezidi experience & Yezidi experience \\
\hline 1: The foods restricted in Yezidi culture. & $p<.001$ & 12.29 & 24.55 \\
\hline 2: The Yezidi eating rituals and fasting practices. & $p=.002$ & 13.00 & 23.18 \\
\hline 7: The Yezidi perception and treatment of persons with physical disabilities & $p=.029$ & 18.98 & 11.77 \\
\hline 8: Yezidi indigenous healing practices for mental illnesses. & $p=.033$ & 18.98 & 11.77 \\
\hline 9: Yezidis conceptualization of mental disorders. & $p=.045$ & 18.83 & 12.05 \\
\hline 18: Most respectful and disrespectful behaviors in the Yezidi culture. & $p=.001$ & 20.17 & 9.50 \\
\hline 20: The acceptable proximity in communication with Yezidis. & $p=.010$ & 19.48 & 10.82 \\
\hline 21: Physical contact in the Yezidi culture. & $p=.025$ & 19.07 & 11.59 \\
\hline
\end{tabular}


international and local NGOs concerning the Yezidi culture, and as a result, no differences were found based on the type of organization in the knowledge of Yezidi culture among aid workers. A Kruskal-Wallis test was conducted to compare each of the 22 variables concerning the two types of organizations. A significant difference was found only in one question, Q18-Most respectful and disrespectful behaviors $(p=0.037$; mean rank for Q18: international NGOs $=23.57$, local NGOs $=16.22$ ).

In addition, multiple linear regression was conducted to predict the value of the knowledge of the Yezidi culture (the questionnaire total score) based on the value of the type of organizations and aid workers experience with Yezidi IDPs. These variables only partially predicted the knowledge of Yezidi culture, $F$ $(2,34)=4.503, p<.018, R^{2}=.209$, indicating that the two independent variables, type of organization and aid workers experience with Yezidi IDPs, predict only $20.9 \%$ of the variability. Only the experience with Yezidis added statistically significantly to the prediction, $p<.027$. The type of organization was not significant.

\section{Analysis of major dimensions of the Yezidi culture relevant for humanitarian programs among aid workers in Iraqi Kurdistan}

The eight major dimensions were calculated based on the questionnaire that was used in the study which was developed from the IASC (2007) guidelines. The eight major dimensions that the IASC (2007) promoted were food, water and sanitation, shelter/family structure, religion, health, education, community, and communication. The scores of each question within one of these dimensions were combined in SPSS (version 23) and calculated by creating new variables. For example, the "food" dimension consisted of variables Q1 and Q2. The scores were combined for each participant and put into a new variable labeled "food" for the dimension.

The major dimensions of the Yezidi culture relevant for humanitarian programs were compared using Friedman test. The Friedman test was first applied to the total dataset that included all 37 participants, which revealed that the participants' knowledge of Yezidi culture varied significantly across the eight dimensions, $X^{2}(7, N=37)$ $=30.366, p<.001$. The Yezidi participants were then removed, and the test was applied to the remaining 32 participants, which revealed that the participants' knowledge of Yezidi culture still varied significantly across the eight dimensions.

The dimension that scored the lowest in both results was the water and sanitation, while the highest scored dimension was education for both results. The high score in education could be because the public education system in Iraq is similar all over the country and does not differ between ethnicities or regions. The water and sanitation being lowest could be that while both the Yezidi and Islam religions use water before prayer, there are still major differences between the two religions since the Yezidi concept of holy water is different than in Islam. This would explain why the scores on the first test that included the Yezidis were higher than the second test, which only included non-Yezidi participants. In fact, when the Yezidi participants were removed from the second test, three other dimension scores decreased in results: food, community, and communication. In contrast, the dimensions of religion, health, education, and shelter and family structure scores were consistent between the two groups.

Next, the multiple linear regression analysis was conducted to predict the value of the knowledge of the Yezidi culture on the eight major dimensions: food, water and sanitation, shelter/family structure, religion, health, education, community, and communication. The Health variable was predicted by the community, communication, and education variables, $F(7,29), p<.0005$, $R^{2}=.789$, indicating that these variables predict $78.9 \%$ of the variability. However, for the knowledge of the community, the values of the partial and part correlations dropped sharply from the zero-order correlation, indicating that much of the variance in Health explained by knowledge of the community is also explained by other variables. Also, tolerance scores showed that over $50 \%$ of the variance can be explained by the other predictors. Finally, a variance inflation factor (VIF) greater than 2 is usually considered problematic, and all three variables have VIF greater than 2 .

The Religion variable was also predicted by communication and education variables, $F(7,24), p<.0005, R^{2}$ $=.732$, indicating that these variables predict $73.2 \%$ of the variability. Although the values of the partial correlations did not change much for both communication and education, the part correlations dropped from the zero-order correlation, indicating that much of the variance in Religion is explained by the knowledge of the communication and education but also is explained by other variables. In addition, tolerance scores showed that over $30 \%$ of the variance can be explained by the other predictors, and both communication and education variables had VIF greater than 2.

\section{Factor analysis of variables of the Yezidi culture relevance for humanitarian programs}

Exploratory factor analysis (EFA) was conducted to measure the construct validity of the questionnaire, which is discussed in detail in the next section, but it also revealed some results for understanding the interrelations between the variables. The overall results of the factor analysis are shown in Table 2. 
Table 2 Factors and correlated questions

\begin{tabular}{|c|c|c|c|}
\hline $\begin{array}{l}\text { Factor } \\
\text { 1'number }\end{array}$ & Factor name & Correlated questions & Significance \\
\hline \multirow[t]{4}{*}{1} & \multirow[t]{4}{*}{$\begin{array}{l}\text { Mental health } \\
\text { and disability }\end{array}$} & $\begin{array}{l}\text { Q9-Explanation of mental } \\
\text { illnesses }\end{array}$ & 0.894 \\
\hline & & $\begin{array}{l}\text { Q8-Traditional healing } \\
\text { practices for mental illnesses }\end{array}$ & 0.894 \\
\hline & & $\begin{array}{l}\text { Q7-Perception of physical } \\
\text { disability }\end{array}$ & 0.833 \\
\hline & & $\begin{array}{l}\text { Q17-The roles of men and } \\
\text { women }\end{array}$ & 0.733 \\
\hline \multirow[t]{3}{*}{2} & \multirow{3}{*}{$\begin{array}{l}\text { Family and } \\
\text { healing practices }\end{array}$} & Q4_Family & 0.886 \\
\hline & & $\begin{array}{l}\text { Q6-Traditional healing } \\
\text { practices for physical illnesses }\end{array}$ & 0.857 \\
\hline & & Q5-Living arrangements & 0.821 \\
\hline \multirow[t]{5}{*}{3} & \multirow[t]{5}{*}{ Rituals } & $\begin{array}{l}\text { Q22-Restrictions in } \\
\text { communication }\end{array}$ & 0.786 \\
\hline & & $\begin{array}{l}\text { Q2-Eating and fasting } \\
\text { rituals }\end{array}$ & 0.727 \\
\hline & & $\begin{array}{l}\text { Q14_Funeral and burying } \\
\text { rituals }\end{array}$ & 0.708 \\
\hline & & Q16_Social status & 0.665 \\
\hline & & Q1-Restricted foods & 0.623 \\
\hline \multirow[t]{3}{*}{4} & \multirow{3}{*}{$\begin{array}{l}\text { Water and } \\
\text { religion }\end{array}$} & Q3-Water and sanitation & 0.876 \\
\hline & & $\begin{array}{l}\text { Q12-Religious beliefs and } \\
\text { practices }\end{array}$ & 0.772 \\
\hline & & $\begin{array}{l}\text { Q13_Holy places and } \\
\text { pilgrimage }\end{array}$ & 0.643 \\
\hline \multirow[t]{3}{*}{5} & \multirow[t]{3}{*}{ Behaviors } & Q19_Holiday & 0.840 \\
\hline & & Q11_Coping with hardships & 0.636 \\
\hline & & Q18-Behavior & 0.635 \\
\hline
\end{tabular}

The first rotated factor "mental health and disability" is most highly correlated with Q9-Explanation of mental illnesses (0.894), Q8-Traditional healing practices for mental illnesses (0.833), Q7-Perception of physical disability (0.733), and Q17-The roles of men and women (0.711). The second factor "family and healing practices" is highly correlated with Q4-Family (0.886), Q6-Traditional healing practices for physical illnesses (0.857), and Q5-Living arrangements (0.821). The third factor is correlated with Q22-Restrictions in communication (0.786), Q2-Eating and fasting rituals (0.727), Q14-Funeral and burying rituals (0.708), Q16-Social status (0.665), and Q1-Restricted foods (0.623). The fourth factor "water and religion" is correlated with Q3-Water and sanitation (in Yezidi culture, water from holy places is used for healing; 0.876), Q12-Religious beliefs and practices (0.772), and Q13-Holy places and pilgrimage (0.643). The fifth factor is correlated with Q19-Holiday (0.840), Q11-Coping with hardships (0.636), and Q18-Behavior (0.635). The sixth factor included variables that showed low correlations, except for
Q19-Yezidi holidays and therefore was excluded from further analysis.

\section{Reliability and validity of findings}

Reliability of the humanitarian questionnaire was tested with Cronbach's alpha and Guttmann's lower bound coefficients. As some research methodologists believe that Cronbach's alpha does not measure internal consistency, Guttmann's lower bound coefficient was used to counterbalance that issue as it does measure internal consistency (Zinbarg et al. 2006). The results indicated a high level of internal consistency for the questionnaire with this specific sample (alpha 0.912 and lambda 1-6 0.870-0.984).

Construct validity of the questionnaire was tested with EFA. The results allow for suggesting that minimal standards of validity for the questionnaire were met. Multicollinearity assumption was met at the minimum standard with the determinant score of $4.018 \mathrm{E}-0.11$. Sampling adequacy, based on the Kaiser-Meyer-Olkin (KMO) measure of sampling adequacy, was 0.585 and met the required minimum (above 0.50) for the overall data set indicating that at least $58 \%$ of variance might be caused by underlying factors. The KMO measure for each individual variable showed good results (above $0.50)$ on 20 questions, except for Q1-Food restrictions (0.313) and Q3-Water and sanitation practices (0.332). Removing these two questions would not improve much of the overall validity; therefore, the answers to these questions were left for further analysis. Bartlett's test of sphericity with a significance of $p<.0005$ showed that the data suitability for factor analysis was good. Also, the $32 \%$ of non-redundant residuals with absolute values greater than .05 showed that this model was a good fit.

Based on the Kaiser criterion, the average extracted communalities should be at least more than 0.70 when there are less than 30 variables (Field 2009). In this study, all but Q10-Perceptions of mental disorders (0.684) and Q21-Physical contact (0.622) were above 0.70 , which indicates that 20 out of 22 extracted components represent the variables very well. The rotated eigenvalues determined six factors with eigenvalues greater than 1 and account for $79 \%$ of the variability in the original variables suggesting that there are latent influences associated with other factors. The rotation method was varimax with Kaiser normalization. A rotated matrix indicated six factors with at least three variables per factor with factor loading above 0.4 (have moderate significance) and above 0.5 (have significance). Out of those six factors, three factors included at least three variables with loadings above 0.7 .

The construct validity threats included hypothesis guessing, evaluation apprehension, and experimenter expectancies. In this study, the questionnaire was apparent 
in the subject matter, which was about Yezidi culture. However, since there was no reward or remuneration for being a part of the study, the participants would be less likely to change their answers in the hopes that it is what the researcher wants. Evaluation apprehension leads to the participants modifying their answers to be perceived as intelligent (Warner 2013). This study could potentially be threatened by such bias; however, the results of both the non-Yezidi and Yezidi participants did not appear to be modified for this reason. The participants knew that the researcher was not affiliated with their employers in any way and that their answers were treated as confidential. In the current study, the researcher did not interact with the participants until the participants completed the questionnaire individually which eliminated the threat of experimenter or research expectancies.

External validation includes population validity and ecological validity. Population validity is how well the representation of the sample is to the population as a whole (Warner 2013). In this case, it would be how well the participants represent the rest of the local aid workers in Iraqi Kurdistan. This study did not reach the total number of participants that was initially sought, so the results might not be indicative of the entire population of local humanitarian aid workers, as there are many in Iraqi Kurdistan throughout many different locales. Future research on this topic could obtain more participants in this population to increase population validity. Ecological validity determines how well the results can be generalized across settings. In this study, the questionnaires were conducted in a variety of different settings with local humanitarian aid workers with the findings showing similar results for the participants. The settings included on site locations within IDP camps, in the NGOs' local headquarters, and at a smaller branch in the Dohuk region of Kurdistan.

\section{Summary of quantitative study}

The data obtained from the study were analyzed and provided good suggestions for answering the research questions. Both hypotheses were found to be accurate germane to not providing cultural awareness training for the Yezidi culture, and the prediction that international humanitarian organizations would not provide culturally relevant humanitarian programs to the Yezidi IDPs. Although the initial goal of the study was to conduct data analysis using parametric tests such as the ANOVA and MANOVA, the real-world scenario of collecting data in an armed conflict zone did not allow for the required number of participants needed to meet assumptions for these tests. Nonparametric tests were then used to compare the total scores, the eight dimension scores, and the variable scores obtained on the humanitarian questionnaire. The findings suggested that while there was a difference in the aid workers' knowledge of Yezidi culture between the three groups' (Yezidi participants, non-Yezidi participants with experience working with Yezidis, and non-Yezidi participants with no or little experience working with Yezidis) scores, no significant difference was found when the Yezidi participants were removed. However, there were several individual variables in which a significant difference between the two non-Yezidi groups was indicated by the results. Reliability and construct validity tested with EFA showed results in line with minimal standards required. The five factors derived in EFA are further discussed in the next section.

\section{Discussion}

\section{Major factors of knowledge of the Yezidi culture}

The quantitative portion of the study displayed several interesting findings including the exploratory factor analysis which was conducted to test the validity of the questionnaire. The correlations of the five categories are shown in Table 2 but each category is addressed throughout this section as to why those specific variables are correlated to the specific category.

The first factor was "mental health and disability" which significantly correlated with "explanation of mental illnesses," "traditional healing practices for mental illnesses," "perception of physical disability," and "the roles of men and women." The highest correlations for the variables in this factor were all directly related to the topic of mental health and disability. From the Western perspective, the roles of men and women would not seem directly related to the topic of mental health and disabilities. However, from the participants' perspective, this variable can be related to the topic of health and particularly mental health because in Iraq, and other parts of the Middle East, men are perceived and usually take on the role of the religious leaders who tend to explain and provide treatment for mental health illnesses. Men in these roles are also the holders of traditional healing practices for that specific religion or culture. Moreover, males are dominant in the medical field that provides aid for physical disabilities as well, which further suggests why this question was highly correlated with the other three questions.

The second factor was "family and healing practices" which is grouped with such variables as "Yezidi family," "traditional healing practices for physical illnesses," and "living arrangements." The first and last two variables correlated within this factor are directly related to each other because both variables involve the family structure and how the cultural family values are perceived in relation to the family structure, which is directly related to how the family resides. It is especially important that they correlate because displacement often forces families 
to often reside in one tent or one room in an abandoned building and the aid workers who had experience with Yezidis would see and learn about the Yezidi family structure and living arrangements. As for those participants who did not have experience with Yezidis, it is common for Kurdish and other ethnicities in the Middle East to share houses and residencies with large families. The relationship between "traditional healing practices for physical illnesses" and "Yezidi family" could be explained from the participants' perspective, as the family is often sought out for traditional healing practices for physical illnesses first in lieu of seeking advice from a medical doctor. The traditional healing practices could also vary from family to family which suggests that if someone wanted a traditional healing practice, they might go to an individual in their extended family who is an elder. Another explanation of this relationship could be that traditional healing services are provided in the healer's living arrangements, since displaced Yezidi Sheikhs who provide healing services do not have space other than their tent in the IDP camp or in another shelter that they occupy with their families.

The third factor was "rituals," and it was correlated with "restrictions in communication," "eating and fasting rituals," "funeral and burying rituals," "social status," and "restricted foods." This factor contained five different correlated variables within it. Four of the variables are all related to customary rituals that include eating, food, communication, and funeral rituals. One variable, "social status," may not seem directly related to the other four variables. However, when speaking about rituals in the Yezidi culture, as well as in other Middle Eastern cultures, the individuals who lead, start, or teach individuals about the rituals are often leaders among the community, and often looked upon as the individuals with the highest status in the community. This reasoning suggests that it is not a coincidence that the variable of social status was correlated to others within this factor.

The fourth factor was "water and religion," and it was correlated with "water and sanitation" (in the Yezidi culture, water from holy places is used for blessing individuals), "religious beliefs and practices," and "holy places and pilgrimage." All three variables within this factor are directly related to the Yezidi culture and other cultures in the Middle East concerning water and religion. The connection between the washing before prayer in both religions (Yezidism and Islam) indicates why these factors correlated. Moreover, it explains whether the Kurdish participants were aware of any differences in the meaning of the sacred water in the Yezidi culture.

The fifth and final factor that is discussed is the "cultural behaviors" factor that is correlated with "holiday," "coping with hardships," and "behavior." The correlation of three variables is interesting and suggests that they all were related to cultural behaviors. The variable "holiday" is more related to the behaviors in a religious context while "coping with hardships" is related to the current situation of the Yezidi population and how they were coping with hardships of displacement. However, because the Yezidi and Kurdish cultures are so intertwined with their respective religious beliefs, it makes sense that these two variables are highly correlated because their behaviors of coping are primarily all through their religious practices and through their religious leaders.

As per the results from the data reporting above regarding the differences between the participants who had experience working with Yezidis and those who did not, the results were quite surprising in that it was thought that those participants with experience working with Yezidis would rate themselves as knowing more about the Yezidi culture. However, the findings seemed to suggest the opposite. The variables that were in favor of each group of participants are listed in Table 3.

It is an interesting find with these six variables that the participants who had not previously worked with the Yezidi population outscored those participants who did have experience working with the Yezidi population. However, when analyzed, it is suggested that because the participants had no experience working with Yezidis, they possibly viewed the Yezidi population as actually Kurds. The participants answered in accordance with their own practices and culture in mind and did not make a distinction between the Yezidi culture and their own Kurdish culture. With the participants who had experience working with the Yezidi population, however, their knowledge of the Yezidis had been challenged and possibly modified through the experience of working with the population firsthand. This would convey the realization to the aid workers that the Yezidi culture and values are different from the Kurdish culture and values and the fact that Yezidi culture is changing could add 
more confusion, thus resulting in lower scores for the participants who had experience working with Yezidis.

Even though most of the variables favored the participants with no Yezidi experience, two favored the participants who did have experience working with Yezidis, shown in Table 3.

These two variables correspond to the topic of food and eating practices, which are essential to humanitarian aid. Regardless of the population, humanitarian aid workers would quickly learn the different food restrictions because for the population to eat and live, the organizations must adhere to their restrictions, rituals, and practices. Another pertinent suggestion as to why the experienced participants had more knowledge of this particular topic than the non-experienced group of participants is because of the fasting rituals that the Yezidis practice. It was found in a previous study (Msall 2016) that the Yezidis continued to practice their fasting as well as their eating rituals in their displacement situation without any significant change. The fact that they did continue these traditions suggests that the participants working with the Yezidi population had interactions with Yezidis regarding these elements of their culture, which would lead to higher scores on these questions in particular. Also, the first and the most frequently provided type of aid by humanitarian organizations is food in order to meet the IDPs' immediate basic need for survival. Therefore, the experience of aid workers with Yezidi IDPs was most likely related to food distribution through which they could learn Yezidi food and eating practices.

\section{Conclusion}

Humanitarian organizations which work with minority populations need to apply a research-based approach that would allow timely, adequately, and culturally relevant response to the target populations' basic human needs such as food, water, and shelter, as well as health care, education, and community development. These organizations would provide such aspects to the displaced at first; however, doing so through a research-based approach would eliminate cultural mishaps later and might better the relationship between the target population and the organization. Humanitarian organizations that often work in scarce-resource contexts may perceive such recommendation as unaffordable due to the cost of hiring researchers for the in-field data collection and analysis. However, the costs of culturally blind humanitarian programs that possibly impose discrimination in aid distribution, which in turn leads to deterioration of mental health of displaced individuals, may far outweigh expenses of both governmental and nongovernmental organizations responsible for the well-being of these populations.
A major recommendation, based on the current study's findings, for the humanitarian organizations working with Yezidi IDPs, as well as future displaced minority populations, would be to conduct qualitative research among the population the organization is serving. This would allow the NGOs to develop proper cultural awareness training for the aid workers, even though they are local residents, who may not have the knowledge of the minority culture. The goals and services provided by each type of organization (those that work within camps and those that work outside) are also different in nature. Having a sound foundation of what the needs are of the target population and comparing those needs with what the organization provides is essential to modifying those services into culturally relevant programs for the target population. The tools used for interviews among the target population could be based on the IASC guidelines, which would provide a holistic understanding of the target culture while also allowing for open-ended answers that might produce critical details for the organization.

Furthermore, the information gathered from such research could decrease instances of perceived discrimination among minority displaced populations. Including the main religious aspects in cultural awareness training for all aid workers, international and local, would be a strong asset in lessening the perceived discrimination and would help eliminate some of the biases toward Yezidis that non-Yezidis might have which would further decrease the perceived discrimination. Although focusing on the Yezidi population, the implication of the lack of knowledge among local aid workers leading to perceived discrimination among the target population could also be applied to other minority populations in similar situations not only in Iraq but also in other countries and regions around the world. The recommendation and guideline that local aid workers have knowledge about and understand a local minority population's culture is misleading and could lead to perceived discrimination, which further suggests that cultural awareness training should be provided for all aid workers by humanitarian organizations.

The findings suggest that the local and international NGOs working within Iraqi Kurdistan do not provide their aid workers with cultural awareness training concerning the Yezidi culture. It appears that the assumptions of those aid workers with experience working with Yezidis were challenged when they realized that the Yezidi culture is different from the Kurdish culture whereas the aid workers with no or little experience working with Yezidis continued maintaining their assumptions and applied their own beliefs and values to the Yezidis. This was supported by comparing the scores between the non-Yezidi participants who did and did not have experience working with Yezidis, with the 
experienced participants reporting a lower understanding overall. It could also be that the experienced aid workers' knowledge could have been about traditional Yezidi practices, and since these practices are changing, the aid workers could realize that the practices are different from what they previously thought. This was suggested through the emerged factors via the EFA that was conducted on the quantitative data from the aid workers' questionnaires.

Cultural awareness training would be an essential addition to the humanitarian organizations that are working in Iraqi Kurdistan and would certainly tackle the issues discussed above. The training should focus on all non-Yezidi humanitarian aid workers since there is a possibility that they may work with Yezidi IDPs. A strong focus should be on communication with regard to the restriction of saying the word "Satan," religious practices concerning food restrictions, fasting, clothing, and holidays, as well as training for gender-specific issues including female Sheikhs and rape victims. Conducting training with humanitarian aid workers would help bring a sense of cultural relevancy to the organizations and services that the Yezidi IDP participants felt did not exist. This training would also help to preserve the Yezidi culture in a situation where the participants believed that Yezidis were not wanted in the region at all. Although ISIS and the history of Yezidi conflict with both Arabs and Kurds emphasize this point, another important issue is the multiple reports regarding Christian organizations taking advantage of the situation by converting vulnerable Yezidis to Christianity (Rudaw 2015). The cultural awareness training for the non-Yezidi aid workers might encourage these aid workers to support the Yezidi community when they are confronted by the missionary organizations whose priority is to proselytize the Yezidis.

\section{Abbreviations \\ ANOVA: Analysis of variance; CHS: Core Humanitarian Standard; CRP: Culturally relevant programs; CT: Cultural training type of organizations; EFA: Exploratory factory analysis; HAP: Humanitarian Accountability Project; IASC: Inter-Agency Standing Committee; IDPs: Internally displaced persons; ISIS: Islamic State of Iraq and al-Sham; KMO: Kaiser-Meyer-Olkin; MANOVA: Multivariate analysis of variance; MT: Model type of organizations; NCR: No cultural relevance; NGOs: Nongovernmental organizations; VIF: Variance inflation factor}

\section{Availability of data and materials}

Please contact the author for data requests.

\section{Authors' contributions}

The author read and approved the final manuscript.

\section{Author's information}

The author is an Assistant Professor of International Psychology at the American University of Kuwait.

\section{Competing interests}

The author declares that he has no competing interests.

\section{Publisher's Note}

Springer Nature remains neutral with regard to jurisdictional claims in published maps and institutional affiliations.

Received: 4 March 2018 Accepted: 11 June 2018

Published online: 27 June 2018

\section{References}

Abramowitz (2010) Trauma and humanitarian translation in Liberia: the tale of open mole. Cult Med Psychiatry 34:353-379. https://doi.org/10.1007/s1 1013-010-9172-0

Açikyildiz, B. (2014). The Yezidis: the history of a community, culture and religion. N.p.: I. B. Tauris

Bender MS, Clark MJ, Gahagan S (2014) Community engagement approach: developing a culturally appropriate intervention for Hispanic mother-child dyads. J Transcult Nurs 25(4):373-382. https://doi.org/10.1177/ 1043659614523473

Betancourt T, Speelman L, Onyango G, Bolton P (2009) Psychosocial problems of war-affected youth in northern Uganda: a qualitative study. Transcult Psychiatry 46(2):238-256. https://doi.org/10.1177/1363461509105815

Betancourt T, Williams T (2008) Building an evidence base on mental health interventions for children affected by armed conflict. Intervention 6(1):39-56. https://doi.org/10.1097/WTF.0b013e3282f761ff

Choi S, Piazza J (2014) Internally displaced populations and suicide terrorism. J Confl Resolut:1-33. https://doi.org/10.1177/0022002714550086

Copping A, Shakespeare-Finch J, Paton D (2010) Towards a culturally appropriate mental health system: Sudanese-Australians' experiences with trauma. J Pacific Rim Psychol 4(1):53-60. https://doi.org/10.1375/prp.4.1.53

Core Humanitarian Standard. (2014). Core humanitarian standard on quality and accountability. N.P.: Groupe URD, HAP international, people in aid and the sphere project. Retrieved February 2, 2015

Dalyan MG, Dogan C (2013) An overview of 19th century Yezidi women. Asian Soc Sci 9(7):114-123. https://doi.org/10.5539/ass.v9n7p114

Daoud N, Shankardass K, O'Campo P, Anderson K, Agbaria A (2012) Internal displacement and health among the Palestinian minority in Israel. Soc Sci Med 74(8):1163-1171. https://doi.org/10.1016/j.socscimed.2011.12.041

Dominelli L (2014) Internationalizing professional practices: the place of social work in the international arena. Int Soc Work 57(3):258-267. https://doi.org/ $10.1177 / 0020872814522671$

Facchini R (2013) Humanitarian and civic assistance health care training and cultural awareness promoting health care pluralism. Mil Med 178(5):537-542. https://doi.org/10.7205/MILMED-D-13-00006

Field A (2009) Discovering statistics using SPSS. Sage publications. Chicago.

Guest J (1993) Survival among the Kurds: a history of the Yezidis, XVIII edn. Kegan Paul International, London and New York

Humanitarian Accountability Project (HAP) (2010). The 2010 HAP standard in accountability and quality management. https://www.chsalliance.org/files/ files/Resources/Standards/2010-hap-standard-in-accountability.pdf

Inter-Agency Standing Committee (IASC) (2007) IASC quidelines on mental health and psychosocial support in emergency settings. IASC, Geneva

Koska V (2008) Return and reintergration of minority refugees: the complexity of the Serbian returnees experiences in the town of Glina. Politička Misao 45(5):191-217

Levinson D (1998) Ethnic groups worldwide: a ready reference handbook, p 203

Maisel S (2013) Syria's Yezidis in the Kurd Dagh and the Jazira: building identities in a heterodox community. The Muslim World, p 103

Mowafi H (2011) Conflict, displacement and health in the Middle East. Global Public Health 6(5):472-487. https://doi.org/10.1080/17441692.2011.570358

Msall, K. (2016). Cultural relevance of humanitarian programs for Yezidi internally displaced persons in Iraqi Kurdistan (doctoral dissertation, the Chicago School of Professional Psychology)

Nicolaus P (2011) The serpent symbolism in the Yezidi religious tradition and the snake in Yerevan. Iran Caucasus 15:49-72. https://doi.org/10.1163/ $157338411 \times 12870596615359$

Reuter T (2012) Including minority rights in peace agreements: a benefit or obstacle to peace processes after ethnic conflicts? Int J Minor Group Rights 19(4):359-397. https://doi.org/10.1163/15718115-01904002

Roumani MM (2003) The silent refugees: Jews from Arab countries. Mediterr Q 14(3):41-77

Rudaw (2015) Rudaw. Christian aid groups are proselytizing, Yezidi MP

Rydgren J, Sofi D (2011) Interethnic relations in northern Iraq: brokerage, social capital, and the potential for reconciliation. Int Sociol 26(1):25-49. https://doi. org/10.1177/0268580910380981 
Sa'Da C, Serafini M (2013) Humanitarian and medical challenges of assisting new refugees in Lebanon and Iraq. Forced Migrat Rev 44:70-73

Sonderegger R, Rombouts S, Ocen B, McKeever R (2011) Trauma rehabilitation for war-affected persons in northern Uganda: a pilot evaluation of the

EMPOWER programme. Br J Clin Psychol 50:234-249. https://doi.org/10.1348/ $014466510 \times 511637$

Spät E (2008) Late antique literary motifs in Yezidi oral tradition: the Yezidi myth of Adam. J Am Orient Soc 128(4):663-679

The Sphere Project (2016) Humanitarian Charter and Minimum Standards in Humanitarian Response. http://www.sphereproject.org/about/

United Nations. (1998). Principles and recommendations for population and housing censuses. Statistical Papers, No.67, Sales No E.98.XVII.8.

United Nations High Commissioner for Refugees (2007) UNHCR's eligibility guidelines for assessing the international protection needs of Iraqi asylumseekers. UNHCR, Geneva, Switzerland

Warner R (2013) Applied statistics: from bivariate through multivariate techniques, 2nd edn. SAGE Publications, Inc, Washington, DC

Zinbarg R, Yovel I, Revelle W, McDonald R (2006) Estimating generalizability to a universe of indicators that all have an attribute in common: a comparison of estimators for alpha. Appl Psychol Meas 30:121-144. https://doi.org/10.1177/ 0146621605278814

\section{Submit your manuscript to a SpringerOpen ${ }^{\oplus}$ journal and benefit from:}

- Convenient online submission

- Rigorous peer review

- Open access: articles freely available online

- High visibility within the field

- Retaining the copyright to your article

Submit your next manuscript at $>$ springeropen.com 